\title{
Impacto das funções desempenhadas pelos gerentes nos resultados da incubadora: survey realizada na rede mineira de inovação
}

\author{
José Magno da Silva ${ }^{a *}$, Carlos Eduardo Sanches da Silva \\ Geanete Dias Morais Batistac ${ }^{\mathrm{c}}$, Maurício Pinho Bitencourt ${ }^{\mathrm{d}}$ \\ a*magno@lna.br, UNIFEl, Brasil \\ bcadusanches@uol.com.br, UNIFEl, Brasil \\ 'geanete@incit.com.br, UNIFEl, Brasil \\ dmauricio@incit.com.br, UNIFEl, Brasil
}

\begin{abstract}
Resumo
Este artigo tem como objetivo avaliar as relações entre as funções desempenhadas pelo gerente e os resultados obtidos pela incubadora. São considerados como resultados: o tempo que o gerente ocupa cargo de direção, o tempo de existência da incubadora, o número de empresas incubadas, o número de empresas graduadas e a obtenção da certificação 1SO 9001. As funções desempenhadas pelos gerentes das incubadoras, baseadas nas funções do Escritório de Gerenciamento de Projetos (PMO), são agrupadas e suas descrições são adaptadas ao contexto das incubadoras de empresas. Um questionário foi elaborado e enviado por e-mail às incubadoras de empresas da Rede Mineira de Inovação. Os dados foram coletados, processados estatisticamente e posteriormente analisados, tendo como resultados principais: as funções consideradas mais importantes para se alcançar os resultados da incubadora - participar do planejamento estratégico das empresas incubadas e distribuir recursos disponíveis entre as empresas incubadas - e a de menor importância para a obtenção dos resultados - monitorar e controlar o desempenho de cada plano de negócio das empresas incubadas.
\end{abstract}

Palavras-chave

Incubadoras de empresas. Gerente da incubadora. Funções do gerente. Escritório de gerenciamento de projetos.

\section{Contexto da pesquisa}

Os projetos demandam orientação e controle sistematizados e as decisões devem estar alinhadas às estratégias da organização Desta forma, é essencial facilitar e aperfeiçoar as atividades de gerenciamento de projetos da organização, tendo como ênfase a otimização dos recursos para obtenção de melhores resultados. Um conceito amplamente difundido para desempenhar esta função organizacional é o escritório de gerenciamento de projeto ou conhecido também como Project Management Office (PMO).

A incubadora pode ser considerada como a gestora de um portfólio de projetos em que cada incubada corresponde a um projeto de plano de negócio. As incubadoras de empresas possuem um gestor, que desempenha papel importante para obtenção de resultados: o gerente da incubadora.

Gillotti e Ziegelbauer (2006) identificaram que os fatores críticos de sucesso de uma incubadora são: objetivos claros e bem comunicados; gerente da incubadora; serviços de apoio para o desenvolvimento dos incubados; recursos compartilhados; espaço físico; financiamentos; processo de captação e seleção dos incubados. Esta pesquisa destaca o gerente da incubadora que participa do processo de captação e seleção de incubados, coordena as operações diárias e são fundamentais para o atendimento das metas.

Adkins (2007, p. 20) também identifica como fator crítico de sucesso da incubadora o seu gerente. 0 autor descreve que: 
[...] frequentemente são contratados gerentes de incubadoras sem experiência no cultivo de empresas. Os gerentes podem ser excelentes em gerenciar empresas, mas não possuem a habilidade de 'insuflar vida a um programa de incubação'. No pior dos casos esses gerentes perdem apoio dos stakeholders, os projetos da incubadora correm o risco de tornarem-se buracos negros que sugam e afastam recursos.

Albert e Gaynor (2003) também identificam em suas pesquisas a relevância do gerente da incubadora, porém não exploram este relevante cargo.

Até 1980 , existiam de 10 a 15 incubadoras nos Estados Unidos, o movimento era incipiente, mas rapidamente tornou-se um negócio global (BARROW, 2001). 0 mesmo autor destaca a necessidade de desenvolver teorias coerentes sobre as melhores práticas de gestão das incubadoras. Neste sentido, as pesquisas sobre a gestão das incubadoras se concentraram no estabelecimento de benchmarking e identificação de fatores críticos de sucesso (UNITED..., 2004; WIGGINS; GIBSON, 2003; HARMAN, 2003; LENDNER, 2003; PETERS et al., 2004; HACKETT; DILTS, 2004).

A Allen Consulting Group (2003) realizou um estudo sobre o Building on Information Technology Strengths (BITS) um projeto governamental que visa desenvolver incubadoras de base tecnológica na Austrália. Concluiu-se que as competências dos gerentes das incubadoras possuem relação direta com o desempenho da incubadora. Porém o estudo não quantifica nem detalha esta relação. Asghari (2008) cita que existem cerca de 5.000 pessoas atuando como gerentes de incubadora no mundo.

Esta pesquisa tem como foco o gerente da incubadora e como pergunta de pesquisa:

Qual é a relação entre as funções desempenhadas pelo gerente e os resultados da incubadora?

\section{Incubadora de empresas e o escritório de gerenciamento de projetos}

Incubadoras de empresas fornecem apoio técnico, capacidade de networking, infraestrutura, serviços compartilhados e facilitam o acesso a capital, tornando-se vitais para o desenvolvimento de negócios nas suas fases iniciais (AERTS et al., 2007; ALBERT; GAYNOR, 2001; BOLLINGTOFT; ULHOI, 2005; MARKMAN et al., 2005; PHAN et al., 2005; SIEGEL et al., 2003; WIGGINS; GIBSON, 2003). Em países com mercados emergentes, o uso de incubadoras para o crescimento do setor de pequenas e médias empresas é mais que uma alternativa relevante. Porém existem questionamentos quanto aos resultados advindos da aplicação de recursos nas incubadoras de empresas (MEDEIROS, 1992; BIZZOTO, 2003;
FERREIRA et al., 2008). Neste sentido, surgem estudos para o desenvolvimento de novos modelos de gestão para incubadoras de empresas, com destaque para o Centro de Referência de Novos Empreendimentos (CERNE) proposto pela ANPROTEC.

David et al. (2002) realizaram uma survey em 900 incubadoras do oeste da Europa com o objetivo de estabelecerem parâmetros de benchmarking. Os resultados identificaram que nas incubadoras consideradas benchmarking os gerentes investem $50 \%$ do seu tempo aconselhando os incubados e o tempo restante em questões administrativas, contra 39\% em média das outras incubadoras.

No Brasil, o surgimento das primeiras incubadoras relaciona-se diretamente com o "Programa de Inovação Tecnológica" no âmbito do Conselho Nacional de Desenvolvimento Científico e Tecnológico (CNPq), iniciativa do Governo Federal visando à aproximação entre a academia e a indústria (RAPINI, 2007).

Guimarães et al. (2003) definem incubadora de empresas como ambientes que fornecem assistência às micro e pequenas empresas em sua fase inicial, viabilizando projetos, criando produtos, processos ou serviços, para que essas empresas, após deixarem a incubadora, estejam aptas a se manter no mercado. Identifica-se convergência entre a definição de incubadora de empresas e o Escritório de Gerenciamento de Projetos que é uma estrutura organizacional estabelecida para apoiar os gerentes e as equipes de projetos na implementação de princípios, práticas, metodologias, ferramentas e técnicas para o gerenciamento de seus projetos (DAl; WELLS, 2004). Ambos possuem como objetivo prover meios para que os projetos tenham sucesso. Os primeiros PMOs surgiram na década de 60, de acordo com Murphy (1996), junto com o computador e a propagação de seu uso, e tinham a finalidade de oferecer suporte operacional aos softwares de programação e controle utilizados na gestão de projetos. Segundo o autor, os projetos eram grandes e complexos e esses primeiros PMOs foram estabelecidos em empresas de construção civil e aeroespaciais. Com o passar do tempo, o PMO foi tornando-se parte da maioria das organizações que trabalham com gerenciamento de projetos.

A revisão bibliográfica acerca das funções do PMO está sintetizada no Quadro 1.

Ultimamente, afirma Prado (2003), o PMO é um dos aspectos organizacionais que tem recebido muita atenção de diversos segmentos da indústria. Isto porque ele consegue simplificar, facilitar e otimizar o gerenciamento de projetos a um custo reduzido. 0 autor acrescenta que, em empresas que administram muitos projetos simultâneos, sua utilidade é ainda maior, pois ele alivia o trabalho dos gerentes dos 
Quadro 1. Funções desempenhadas pelo PMO.

\begin{tabular}{|c|c|c|c|c|c|c|c|c|c|c|c|c|c|c|c|}
\hline $\begin{array}{c}\text { Classificação } \\
\text { Hobbs e } \\
\text { Aubry (2007) }\end{array}$ & Função & 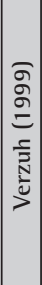 & 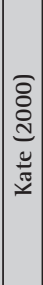 & 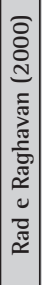 & 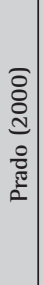 & 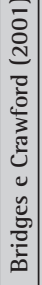 & 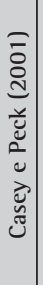 & 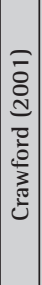 & 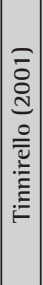 & 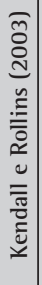 & 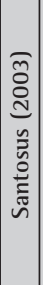 & & 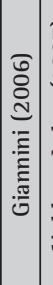 & 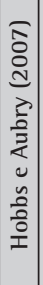 & 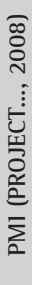 \\
\hline \multirow{6}{*}{$\begin{array}{c}\text { Grupo } 1 \\
\text { Monitoração } \\
\text { e controle do } \\
\text { desempenho } \\
\text { do projeto }\end{array}$} & Relatar o status do projeto para a administração superior & & & & $\mathrm{X}$ & & & & & $\mathrm{x}$ & & & & $\mathrm{X}$ & \\
\hline & Gerar e elaborar documentos e relatórios & & $\mathrm{X}$ & $\mathrm{X}$ & $\mathrm{X}$ & & $\mathrm{x}$ & & & & & $\mathrm{x}$ & & & \\
\hline & Monitorar e controlar o desempenho do projeto & $\mathrm{X}$ & & & $\mathrm{X}$ & & $\mathrm{x}$ & & $\mathrm{X}$ & $\mathrm{x}$ & & & & $\mathrm{X}$ & $\mathrm{X}$ \\
\hline & Implementar e operar um sistema de informações para o projeto & $\mathrm{x}$ & $\mathrm{X}$ & $\mathrm{x}$ & & $x$ & & & $\mathrm{x}$ & $\mathrm{x}$ & & & & $\mathrm{x}$ & \\
\hline & Desenvolver e manter um "placar" para o projeto & & & & $x$ & & & $x$ & & $x$ & & & & $\mathrm{x}$ & \\
\hline & Gerenciar cronogramas & $\mathrm{x}$ & & $\mathrm{X}$ & $\mathrm{X}$ & & & $\mathrm{X}$ & & $\mathrm{x}$ & & $\mathrm{x}$ & & & \\
\hline \multirow{6}{*}{$\begin{array}{c}\text { Grupo } 2 \\
\text { Aprendizagem } \\
\text { organizacional }\end{array}$} & Desenvolver e implementar uma metodologia padrão & $\mathrm{x}$ & $\mathrm{x}$ & $\mathrm{x}$ & $\mathrm{x}$ & $x$ & & $\mathrm{X}$ & $x$ & $\mathrm{x}$ & $\mathrm{x}$ & & & $\mathrm{x}$ & $\mathrm{X}$ \\
\hline & Desenvolver competências do pessoal, incluindo treinamento & $x$ & & $x$ & $\mathrm{X}$ & $\mathrm{x}$ & $\mathrm{X}$ & & $\mathrm{X}$ & $\mathrm{x}$ & & & & $\mathrm{x}$ & $\mathrm{x}$ \\
\hline & Promover o gerenciamento de projeto dentro da organização & $\mathrm{x}$ & & $\mathrm{X}$ & $\mathrm{X}$ & & $\mathrm{x}$ & $\mathrm{X}$ & $\mathrm{X}$ & $\mathrm{X}$ & $\mathrm{X}$ & & & $\mathrm{X}$ & $\mathrm{X}$ \\
\hline & Fornecer mentoring para gerentes de projeto & $\mathrm{X}$ & $\mathrm{x}$ & $\mathrm{X}$ & $\mathrm{x}$ & & $\mathrm{x}$ & $\mathrm{X}$ & & $\mathrm{x}$ & & & & $\mathrm{X}$ & $\mathrm{X}$ \\
\hline & Fornecer um conjunto de ferramentas sem preocupação em padronizar & & & & & & & & & $\mathrm{X}$ & & $\mathrm{x}$ & & $\mathrm{x}$ & $\mathrm{x}$ \\
\hline & Operar ferramentas computacionais e softwares de gerenciamento & & $\mathrm{X}$ & $x$ & $x$ & & $x$ & $x$ & & $\mathrm{X}$ & & $\mathrm{x}$ & & & $\mathrm{x}$ \\
\hline \multirow{6}{*}{$\begin{array}{c}\text { Grupo } 3 \\
\text { Gerenciamento } \\
\text { de multi- } \\
\text { projetos }\end{array}$} & Coordenação entre projetos & $x$ & $\mathrm{x}$ & $\mathrm{X}$ & & & & & $\mathrm{x}$ & & & & & $x$ & \\
\hline & Gerenciar um ou mais portfólios & $\mathrm{x}$ & $\mathrm{x}$ & $x$ & & & & & $\mathrm{x}$ & $\mathrm{x}$ & & & & $\mathrm{X}$ & $x$ \\
\hline & 1dentificar, selecionar e priorizar projetos novos & & $\mathrm{x}$ & $\mathrm{X}$ & $x$ & $\mathrm{x}$ & & & $\mathrm{x}$ & $\mathrm{x}$ & & & & $\mathrm{x}$ & \\
\hline & Gerenciar um ou mais programas & & $x$ & & & & & & & & $\mathrm{x}$ & & & $\mathrm{x}$ & $\mathrm{x}$ \\
\hline & Distribuir recursos entre os projetos & $\mathrm{X}$ & & & & $\mathrm{X}$ & & $\mathrm{X}$ & & & & & & $\mathrm{x}$ & $\mathrm{X}$ \\
\hline & Integrar os vários escritórios e carteiras de projetos & & & & & & & & & & & & $\mathrm{x}$ & & \\
\hline \multirow{5}{*}{$\begin{array}{c}\text { Grupo 4 } \\
\text { Gerenciamento } \\
\text { estratégico }\end{array}$} & Fornecer consultoria para a administração superior & & & $\mathrm{X}$ & $\mathrm{X}$ & & & $\mathrm{X}$ & $x$ & $\mathrm{X}$ & & & & $x$ & \\
\hline & Participar do planejamento estratégico & & $\mathrm{X}$ & $\mathrm{X}$ & & $x$ & $\mathrm{X}$ & & & & & & $\mathrm{x}$ & $\mathrm{X}$ & \\
\hline & Gerenciar benefícios & & & $\mathrm{X}$ & & & & & & $\mathrm{X}$ & & & & $\mathrm{x}$ & \\
\hline & Administrar rede de relacionamentos e monitoração ambiental & & & & & & & & & & & & & $\mathrm{X}$ & $\mathrm{x}$ \\
\hline & Manter a sinergia entre os programas e o Planejamento Estratégico & & $\mathrm{X}$ & $\mathrm{X}$ & & $\mathrm{X}$ & $\mathrm{X}$ & & & & & & $\mathrm{X}$ & & \\
\hline \multirow{7}{*}{$\begin{array}{c}\text { Grupo } 5 \\
\text { Melhoria } \\
\text { interna }\end{array}$} & Monitorar e controlar o desempenho do PMO & & & & & & & & & & & & & $\mathrm{x}$ & \\
\hline & Gerenciar arquivos de documentação do projeto & & & $\mathrm{x}$ & & & & & $\mathrm{x}$ & $x$ & $\mathrm{x}$ & & & $\mathrm{X}$ & \\
\hline & Fazer a manutenção de histórico do projeto & & & $\mathrm{x}$ & & & & & $\mathrm{x}$ & & & $\mathrm{x}$ & & & \\
\hline & Gerenciar auditorias do projeto & & $\mathrm{X}$ & & $\mathrm{x}$ & & & & $\mathrm{x}$ & & & & & $\mathrm{x}$ & $\mathrm{x}$ \\
\hline & Gerenciar revisões pós-projetos & $\mathrm{x}$ & & & & & & & & & & & & $\mathrm{x}$ & $\mathrm{X}$ \\
\hline & Criar e gerenciar um banco de dados de lições aprendidas & & & & $\mathrm{x}$ & & $\mathrm{X}$ & $\mathrm{X}$ & $x$ & $\mathrm{x}$ & & $\mathrm{x}$ & & $\mathrm{x}$ & $\mathrm{x}$ \\
\hline & Criar e gerenciar um banco de dados de risco & & & $\mathrm{x}$ & & & $\mathrm{X}$ & $\mathrm{X}$ & $\mathrm{X}$ & $\mathrm{x}$ & & $\mathrm{X}$ & & $\mathrm{x}$ & $\mathrm{x}$ \\
\hline \multirow{7}{*}{$\begin{array}{c}\text { Funções } \\
\text { Adicionais } \\
\text { não incluídas } \\
\text { nos grupos de } \\
\text { funções }\end{array}$} & Gerenciar interfaces com o cliente & & & & & & & & & & & & & $\mathrm{x}$ & \\
\hline & Executar tarefas especializadas para os gerentes de projeto & $x$ & & & & & & & $\mathrm{X}$ & $\mathrm{X}$ & & & & $\mathrm{X}$ & \\
\hline & Recrutar, selecionar, avaliar e definir salários para gerentes de projetos & $\mathrm{X}$ & & $\mathrm{x}$ & $\mathrm{x}$ & $\mathrm{x}$ & & & $\mathrm{X}$ & & & & & $\mathrm{X}$ & \\
\hline & Viabilizar a comunicação alta administração / times operacionais & & $\mathrm{x}$ & & & & & & $\mathrm{x}$ & & & $\mathrm{X}$ & $\mathrm{X}$ & & \\
\hline & Gerenciar mudanças & & & $\mathrm{x}$ & $\mathrm{X}$ & & & $x$ & & & & & & & \\
\hline & Elaborar e desenvolver o marketing e a comunicação dos projetos & & & & & & & & $\mathrm{x}$ & & & & $\mathrm{x}$ & & \\
\hline & Atuar como Sala de Situação ou war room & & & $\mathrm{x}$ & & & & & & & & $\mathrm{X}$ & & & \\
\hline
\end{tabular}

Fonte: Elaborado pelos autores.

projetos pelo compartilhamento de tarefas como planejamento e acompanhamento. Dessa forma, os gerentes de projeto podem empregar maior tempo gerenciando seu projeto.

0 gerente da incubadora é o agente de intervenção mais importante para o sucesso das incubadas. Seu papel é descrito como o de um empresário. Este papel, como todo outro aspecto, varia grandemente entre as incubadoras e inclui uma série de responsabilidades como rede de relacionamentos, conselheiro, fornecedor de apoio emocional, expertise em diversas áreas, marketing, operações empresariais, finanças e contabilidade (SMILOR; GILL, 1986; CAMPBELL, 1989; RICE; ABETTI, 1992).

Phan, Siegel e Wright (2005) e Cunha (2001) citam o papel dos gerentes das incubadoras na identificação do mercado para a inovação, no qual estes se apresentam como elementos fundamentais no 
processo de troca de informações entre as empresas incubadas e o mercado.

0 Quadro 2 sintetiza as funções do gerente da incubadora encontradas na literatura.

0 Quadro 3 apresenta algumas funções do PMO sendo confrontadas com funções do gerente da incubadora encontradas na bibliografia.

A análise do Quadro 3 permite a visualização de semelhanças entre funções do PMO e funções do gerente da incubadora. Da mesma forma que o PMO opera com os projetos, o gerente da incubadora atua diretamente com as empresas incubadas, acompanhando sua evolução e lhes oferecendo o apoio necessário para alcançarem o sucesso.

\section{Desenvolvimento da survey}

Segundo Gil (2002), survey caracteriza-se pelo questionamento direto das pessoas para conhecer seu comportamento. Segundo Pinsonneault e Kraemer (1993), a pesquisa survey pode ser classificada quanto ao seu propósito em explicativa, exploratória ou descritiva. Com base na classificação proposta por Pinsonneault e Kraemer (1993), quanto ao propósito, esta pesquisa é explicativa devido ao seu objetivo.

Esta pesquisa utilizou etapas propostas por Pinsonneault e Kraemer (1993), Fink (1993) e Forza (2002).

Quadro 2. Funções do gerente da incubadora.

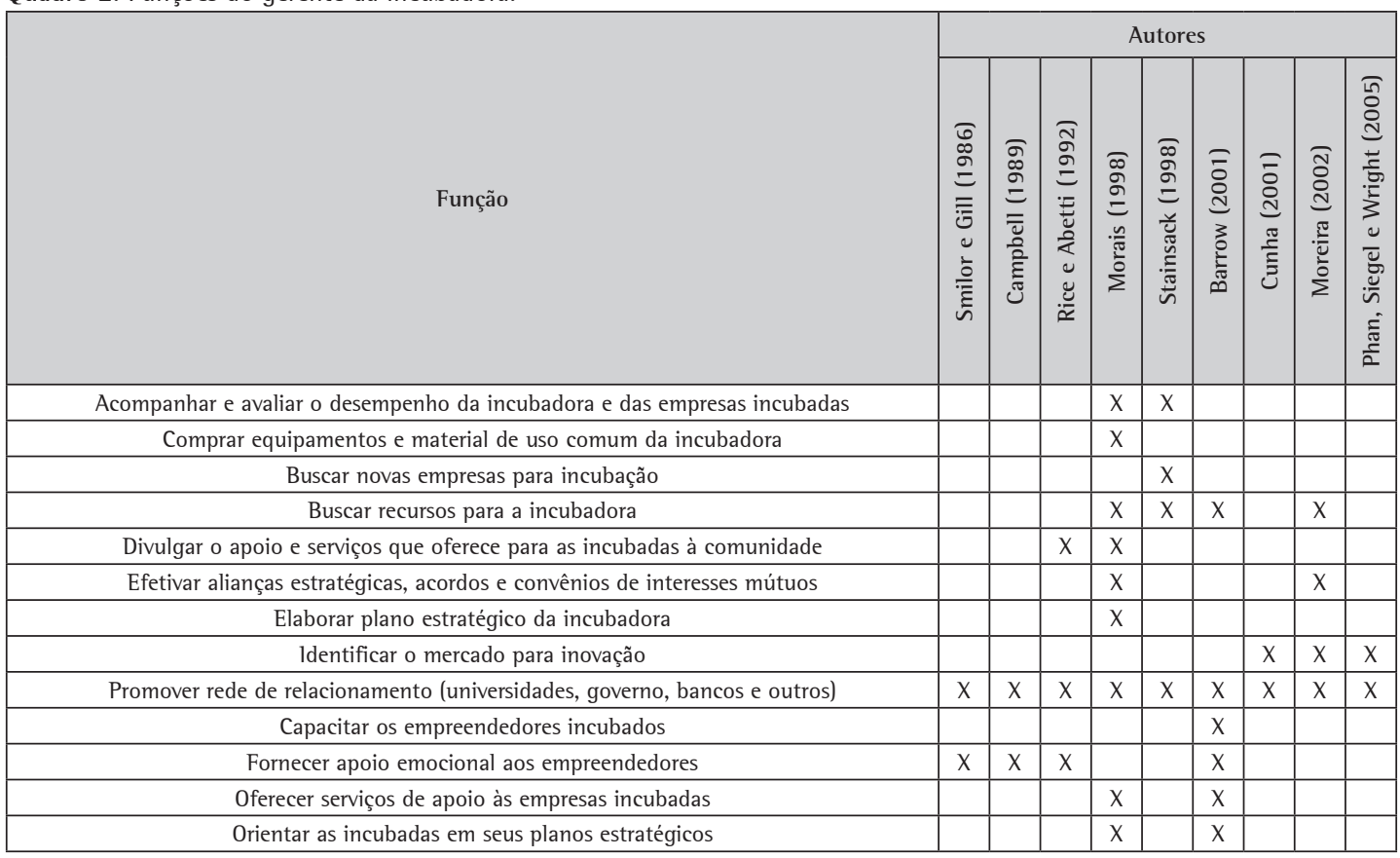

Fonte: Elaborado pelos autores.

Quadro 3. Similaridades entre funções: PMO x gerente da incubadora.

\begin{tabular}{|c|c|}
\hline Função do PMO & Função do gerente \\
\hline Monitorar e controlar o desempenho do projeto & Acompanhar e avaliar o desempenho da incubadora e das empresas incubadas \\
\hline ldentificar, selecionar e priorizar projetos novos & Buscar novas empresas para incubação \\
\hline Distribuir recursos entre os projetos & Buscar recursos para a incubadora \\
\hline Elaborar e desenvolver o marketing e a comunicação dos projetos & Divulgar o apoio e serviços que oferece para as incubadas à comunidade \\
\hline Administrar rede de relacionamentos e monitoração ambiental & Efetivar alianças estratégicas, acordos e convênios de interesses mútuos \\
\hline Manter a sinergia entre os programas e o Planejamento Estratégico & Elaborar plano estratégico da incubadora \\
\hline Administrar rede de relacionamento e monitoração ambiental & Promover rede de relacionamento (universidades, governo, bancos e outros) \\
\hline Desenvolver competências de pessoal, incluindo treinamento & Capacitar os empreendedores incubados \\
\hline Fornecer mentoring para os gerentes de projetos & Fornecer apoio emocional aos empreendedores \\
\hline Executar tarefas especializadas para os gerentes de projeto & Oferecer serviços de apoio às empresas incubadas \\
\hline Participar do planejamento estratégico & Orientar as incubadas em seus planos estratégicos \\
\hline
\end{tabular}

Fonte: Elaborado pelos autores. 


\subsection{Definição do objetivo da pesquisa}

Identificar e analisar as funções do gerente da incubadora, fundamentado nas funções do Escritório de Gerenciamento de Projetos, e relacioná-las aos resultados da incubadora.

\subsection{População e amostra: incubadoras da rede mineira de inovação}

Segundo Malhotra (2006), população é a soma de todos os elementos que compartilham características em comum. A população para esta pesquisa foi definida como sendo todas as incubadoras associadas à Rede Mineira de lnovação (RMl), uma associação sem fins lucrativos, de Incubadoras, Parques Tecnológicos e Tecnópolis, foi fundada em 4 de agosto de 1997 (REDE..., 2008).

A RMl é uma associação que visa ao estudo, à pesquisa e experimentação de novos modelos socioprodutivos e à respectiva divulgação de informações e conhecimentos técnicos e científicos, com a finalidade de fortalecer o desenvolvimento do empreendedorismo no Estado de Minas Gerais (REDE..., 2008).

A RMI é composta por 25 incubadoras em 13 cidades de Minas Gerais, com 335 empresas vinculadas às incubadoras, gerando 2.450 empregos diretos e indiretos, faturamento bruto das empresas incubadas e graduadas de $\mathrm{R} \$ 134.989 .957,14$ e receita das incubadoras (condomínio e projetos e fomento) de $\mathrm{R} \$$ 3.509.419,85 (REDE..., 2008). As incubadoras da RMl são do tipo: 4 tradicionais (16\%); 8 mistas (32\%); 11 base tecnológica (44\%); e 2 design (8\%).

0 tamanho da amostra, segundo Malhotra (2006), deve ser definido de acordo com o tipo de estudo a ser realizado. A amostra utilizada foi a própria população, ou seja, todas as 25 incubadoras associadas à Rede Mineira de Inovação. A amostra total foi de 17 respondentes com todos os questionários considerados válidos.

\subsection{Meio de aplicação}

Decidiu-se pela survey por e-mail devido às vantagens apresentadas, tais como: menor custo, maior taxa de retorno, melhor controle de amostra, menor quantidade de itens não respondidos, maior rapidez na aplicação, menor tempo de resposta e melhor controle sobre os não respondentes (SIMSEK, 1999). 0 autor afirma que o grande problema da survey por e-mail é o possível comprometimento da extensão das conclusões para a população devido ao desconhecimento da população a ser pesquisada.
No entanto, no caso deste estudo, esta dificuldade não foi encontrada pelo fato de ter-se utilizado o catálogo da RMl, no qual estavam relacionadas todas as incubadoras associadas.

\subsection{Elaboração do instrumento}

0 estudo envolveu pesquisa de campo, com aplicação de questionário eletrônico junto aos gerentes das incubadoras de empresas, associadas à Rede Mineira de lnovação, observando os aspectos ligados às suas funções. 0 questionário, constituído por 22 questões, utilizou uma escala de 1 a 4 para a manifestação dos respondentes buscando-se evitar que as respostas tendessem para um ponto médio. Foi dado peso "1" para "sem importância", peso "2" para "pouco importante", peso " 3 " para "importante" e peso "4" para "muito importante". Buscou-se identificar e quantificar, através desta escala, as funções desempenhadas pelos gerentes das incubadoras. 0 questionário baseou-se na revisão bibliográfica acerca das funções do PMO e na pesquisa de Hobbs e Aubry (2007), envolvendo quinhentos PMOs ao redor do mundo, com ênfase aos localizados nos EUA, Canadá e Europa e que resultou no agrupamento das funções do PMO.

\subsection{Validação do instrumento}

Para se avaliar a confiabilidade do questionário, foi calculado o grau de homogeneidade do conjunto de respostas por meio do Alfa de Cronbach, uma vez que ele fornece valores de consistência interna, possibilitando avaliar a escala utilizada (HAIR JUNIOR et al., 2005). A validade interna refere-se às condições de aplicação do instrumento, no caso, o questionário. Nesta pesquisa, calculou-se o valor do Alfa de Cronbach utilizando-se o software Minitab $15^{\circ}$, tendo como agrupamento a tabela completa. 0 menor resultado obtido foi 0,7798 , que atende às condições recomendadas. Tem-se assim a validação do questionário utilizado. Embora não haja um padrão absoluto, valores de Alfa de Cronbach iguais ou superiores a 0,70 refletem uma fidedignidade aceitável (NUNNALLY; BERNSTEIN, 1994; HAIR JUNIOR et al., 1998). Por outro lado, Malhotra (2006) recomenda como critério de decisão, para que "o Alfa de Cronbach seja considerado aceitável, índices acima de 0,6 e, quanto mais próximo de 1, maior a confiabilidade".

A validade externa, segundo Campbell e Stanley (1979), relaciona-se com a representatividade da amostra, a correspondência entre os respondentes e a unidade de análise. Segundo Babbie (2005), uma 
taxa de resposta considerada adequada é 50\%, uma taxa de 60\% é considerada boa e uma taxa de 70\% ou mais é considerada muito boa. 0 autor considera que estas taxas não têm base estatística e que a honestidade nas respostas tem uma importância muito maior que uma alta taxa de resposta. Assim, a validade externa foi obtida fundamentando-se em que: 68\% dos questionários foram respondidos; os respondentes ocupavam cargo de gerência; e, em todos os tipos de incubadora, obteve-se uma taxa de resposta superior a 50\%.

\subsection{Coleta dos dados}

Foram executadas duas rodadas de envio de 23 questionários, visto que 2 questionários foram respondidos pelos gerentes das incubadoras depois do pré-teste. Após a primeira rodada de envio, aguardou-se um prazo de duas semanas para a manifestação dos respondentes. Até o final do prazo, retornaram 6 questionários, ou seja, 17 não haviam sido respondidos.

Por telefone, foram contatados os gerentes das incubadoras restantes e verificada a desatualização do catálogo da RMl no que se refere a gerente responsável, número de telefone, endereço e outros desvios.

Superados os obstáculos, com os novos endereços e feitos novos contatos por telefone, ocorreu a segunda rodada de envio. Eliminados os três casos citados no parágrafo anterior, foram reenviados 14 questionários e 9 foram respondidos. Dos 5 questionários restantes, a não participação foi justificada por falta de tempo, por haver outros questionários a serem respondidos, entre outras razões.

Das 17 incubadoras respondentes, duas incubadoras possuem certificação 1SO 9001:2000, a média de tempo de funcionamento das incubadoras pesquisadas é de 7,5 anos, sendo que a mais antiga tem 17 anos e a mais nova, apenas 2 anos. Da população pesquisada, $47 \%$ das incubadoras têm 5 anos ou menos e 29\% têm 10 anos ou mais. A média de empresas incubadas é 5 , tendo como extremos 1 e 16 empresas incubadas. A média de graduadas é 8 , sendo os extremos 0 e 36 empresas graduadas.

\subsection{Análise preliminar dos dados}

Primeiramente confeccionou-se o boxplot, conforme Figura 1, no software Minitab $15^{\circledR}$.

Analisando a Figura 1, identificamos que as funções 2, 5, 6, 13 e 14 possuem outliers, que serão considerados nas análises subsequentes. As funções 9 e 15 foram consideradas por todos os respondentes como "muito importante" (nota 4), assim sendo, não apresentaram nenhuma variabilidade e foram excluídas dos cálculos posteriores.

A transformação das questões respondidas no questionário seguiu as etapas: cada linha corresponde a um dos 17 respondentes e as colunas às 22 questões respondidas; cada questão respondida foi convertida em um número que mensura o grau de importância de cada uma das 22 funções da incubadora (questões), usando uma escala de 1 (sem importância), 2 (pouco importante), 3 (importante) e 4 (muito importante). Por exemplo: a questão 18 descreve como função da incubadora "reduzir o tempo de incubação", se o respondente atribuiu em sua resposta o grau "importante", esta função foi transformada no valor "3". Este procedimento foi realizado para todas as questões; os valores atribuídos para cada função (coluna) foram somados, obtendo-se o "grau de importância total absoluto"; a ordenação do grau de importância das funções foi realizada considerando que todos os 17 respondentes atribuíram para a mesma função analisada o grau "muito importante", assim, todas teriam valor correspondente a "4", ou seja, 100\% dos respondentes consideram esta função "muito importante". Assim teremos, como soma dos valores da coluna que representa esta função, 68 (17 respondentes que atribuíram à função o mesmo grau de importância - "muito importante", cujo valor é 4 , ou seja, $4 \times 17=68$ ). Para o calculo da linha do "grau de importância ordenado relativo" de cada questão, dividiu-se o "grau de importância absoluto" por "68".

Utilizando os dados tabulados, obteve-se a Tabela 1, que descreve as funções do gerente da incubadora, de acordo com os respondentes, devidamente ordenadas.

Analisando-se a Figura 1, identifica-se que:

- As funções "Monitorar e controlar o desempenho geral da incubadora (F09)" e "Fornecer orientação para os empreendedores incubados (F15)" foram

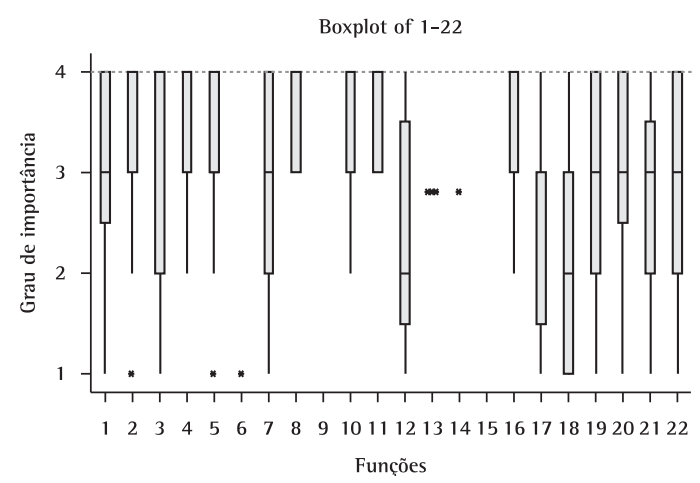

Figura 1. Boxplot dos graus de importância atribuídos às funções do gerente da incubadora. Fonte: Elaborado pelos autores. 
Tabela 1. Funções ordenadas dos gerentes das incubadoras.

\begin{tabular}{cccccc}
\hline \multicolumn{5}{c}{ Incubadores (\%) } \\
\hline Função & Tradicional & $\begin{array}{c}\text { Base } \\
\text { tecnológica }\end{array}$ & Mista & Design & Todas \\
\hline F01 & 75 & 90 & 68 & 50 & 77 \\
F02 & 60 & 100 & 80 & 100 & 87 \\
F03 & 60 & 95 & 70 & 60 & 78 \\
F04 & 90 & 95 & 80 & 100 & 92 \\
F05 & 80 & 90 & 77 & 50 & 80 \\
F06 & 100 & 100 & 87 & 100 & 95 \\
F07 & 75 & 85 & 68 & 50 & 75 \\
F08 & 100 & 90 & 90 & 90 & 92 \\
F09 & 100 & 100 & 100 & 100 & 100 \\
F10 & 90 & 95 & 75 & 90 & 87 \\
F11 & 90 & 90 & 87 & 90 & 90 \\
F12 & 60 & 80 & 40 & 38 & 62 \\
F13 & 90 & 95 & 98 & 100 & 95 \\
F14 & 100 & 95 & 100 & 100 & 97 \\
F15 & 100 & 100 & 100 & 100 & 100 \\
F16 & 100 & 100 & 77 & 90 & 92 \\
F17 & 60 & 60 & 68 & 38 & 65 \\
F18 & 45 & 75 & 40 & 50 & 60 \\
\hline F19 & 75 & 80 & 60 & 90 & 74 \\
F20 & 100 & 75 & 75 & 50 & 78 \\
F21 & 80 & 75 & 65 & 50 & 72 \\
F22 & 75 & 75 & 60 & 60 & 70 \\
\hline & & & & & \\
\hline
\end{tabular}

Grau de importância (simbologia):

Muito importante (4)

Importante (3)

Pouco importante (2)

Fonte: Elaborado pelos autores.

ordenadas como "muito importante" ("grau de importância ordenado relativo" igual a 100\%), seguidas pela função "Desenvolver competências nos empreendedores incubados e em seus colaboradores, incluindo treinamento (F14)" ("grau de importância ordenado relativo” igual a 99\%).

- Em ordem decrescente de importância seguiram-se "Identificar, selecionar e priorizar novas empresas que queiram incubar (F06)”, “Oferecer assessoria especializada para os empreendedores incubados (F13)”, "Orientar a elaboração dos planos de negócio das empresas incubadas (F08)”, "Gerenciar relacionamento dos empreendedores incubados com os interessados em seu empreendimento - fornecedores, clientes, fundos de investimento, organismos governamentais de fomento (F04)", "Fornecer orientação para potenciais empreendedores (F16)" e "Auxiliar e dar suporte aos planos de negócio das empresas incubadas que apresentam problemas (F11)", sendo que estas funções obtiveram "grau de importância ordenado relativo" inferior a 54\%.

As incubadoras foram estratificadas por tipo (Tradicionais, Mistas, de Base Tecnológica e de Design), repetindo-se o mesmo procedimento descrito anteriormente com as funções dos gerentes da incubadora, apresentadas na Tabela 1, e dessa análise obteve-se que:

- As funções "Participar do planejamento estratégico das empresas incubadas (F02)" e "Distribuir recursos disponíveis entre as empresas incubadas (F03)” foram consideradas "muito importante" para as incubadoras de base tecnológica e "pouco importante" para as incubadoras tradicionais.

- As incubadoras de base tecnológica foram as que classificaram o maior número de funções como "muito importante" (64\%) e as incubadoras mistas foram as que apresentaram o menor número de funções classificadas como "muito importante" (32\%).

- As incubadoras de design foram as que apresentaram o maior número funções "pouco importante" (36\%) e o menor número de funções "importante" (9\%).

- As incubadoras tradicionais, de base tecnológica e de design consideraram como funções "muito importante": "Gerenciar relacionamento dos empreendedores incubados com os interessados em seu empreendimento (fornecedores, clientes, fundos de investimento, organismos governamentais de fomento) (F04)", "Monitorar e controlar o desempenho de cada plano de negócio das empresas incubadas (F10)" e "Fornecer orientação para potenciais empreendedores (F16)”. Já, para as incubadoras mistas, estas funções foram consideradas "importante".

- A função "Criar e gerenciar um banco de dados de lições aprendidas pelas empresas incubadas ao longo de seu desenvolvimento (F20)" foi considerada "muito importante" para as incubadoras tradicionais, "importante" para as incubadoras mistas e as de base tecnológica, sendo "pouco importante" para as incubadoras de design.

- As funções "Gerenciar um ou mais portfólio de planos de negócio (F1)" e "Relatar o status do plano de negócio das empresas incubadas para a diretoria e conselho da incubadora, bem como os demais parceiros (F05)" foram consideradas "muito importante" para as incubadoras de base tecnológica, "importante" para as incubadoras mistas e tradicionais e "pouco importante" para as incubadoras de design.

- As funções “Desenvolver e manter um 'placar visível' que permita monitorar simultaneamente todos os planos de negócio das empresas incubadas (F12)" e "Acompanhar as empresas graduadas (F18)" foram consideradas "pouco importante" para as incubadoras tradicionais, mistas e de design e "importante" para as incubadoras de base tecnológica.

- A função "Reduzir o tempo de incubação (F17)" foi considerada "pouco importante" para as incubadoras tradicionais, de base tecnológica e de design e "importante" para as incubadoras mistas. 
Posteriormente fez-se no software Minitab15 a Análise de Cluster por meio do método Ward, obtendo-se como resultado o dendograma da Figura 2.

Considerando um nível de similaridade de 57\%, foi possivel agrupar as funções do gerente da incubadora em oito grupos, conforme o Quadro 4.

As funções 9 e 15, por não apresentarem variabilidade, foram agrupadas em "Focalizar os resultados". Os nomes dados aos grupos foram baseados na classificação da pesquisa de Hobbs e Aubry (2007) sobre as funções do PMO.

Analisando o Quadro 4, identifica-se que os grupos de funções do gerente da incubadora considerados "muito importante" por todos os respondentes são "Focalizar os resultados" e "Captar e selecionar novas empresas"; o grupo de funções com menor grau de importância para todos os respondentes é "Monitorar e controlar o desempenho da execução dos planos de negócios das empresas incubadas"; os respondentes das incubadoras de base tecnológica julgam como função muito importante dos gerentes "Gerenciar multiprojetos de negócios", o que não é compartilhado pelos gerentes dos outros tipos de incubadora; o grupo de funções do gerente da incubadora "Captar e selecionar novas empresas" e "Assessorar os planos de negócio" só não foram considerados muito importantes pelos respondentes das incubadoras mistas.
Uma análise de correlação das funções dos gerentes das incubadoras no software Minitab15 identificou que existe correlação entre as funções dos gerentes da incubadora. Assim, utilizou-se o método de regressão "Mínimos Quadrados Parciais" ou PLS (do inglês Partial Least Square) que aplica-se quando existem: múltiplas variáveis dependentes; preditoras altamente correlacionadas; mais preditoras do que observações (YACOUB; MacGREGOR, 2004; HELLAND, 1988). 0 método PLS reduz o número de preditoras a um conjunto de componentes principais. Portanto, PLS é um método que procura formar componentes que capturam o máximo de informação das variáveis $X$ e que seja útil para predizer Yi, enquanto reduz a dimensionalidade do problema de regressão pela utilização de um número menor de componentes que de variáveis originais (SILVA, 2009).

No caso desta pesquisa, são vinte e duas funções do escritório de gerenciamento de projetos avaliadas $(X)$, sendo identificado que elas são correlacionadas, além da existência de mais preditoras que observações (22 funções do gerente da incubadora contra cinco observações: o tempo que o gerente ocupa cargo de direção, o tempo de existência da incubadora, o número de empresas incubadas, o número de empresas graduadas e a obtenção da certificação ISO 9001).

Os cálculos para análise do PLS foram realizados no software Minibat 15, que segundo Silva (2009),

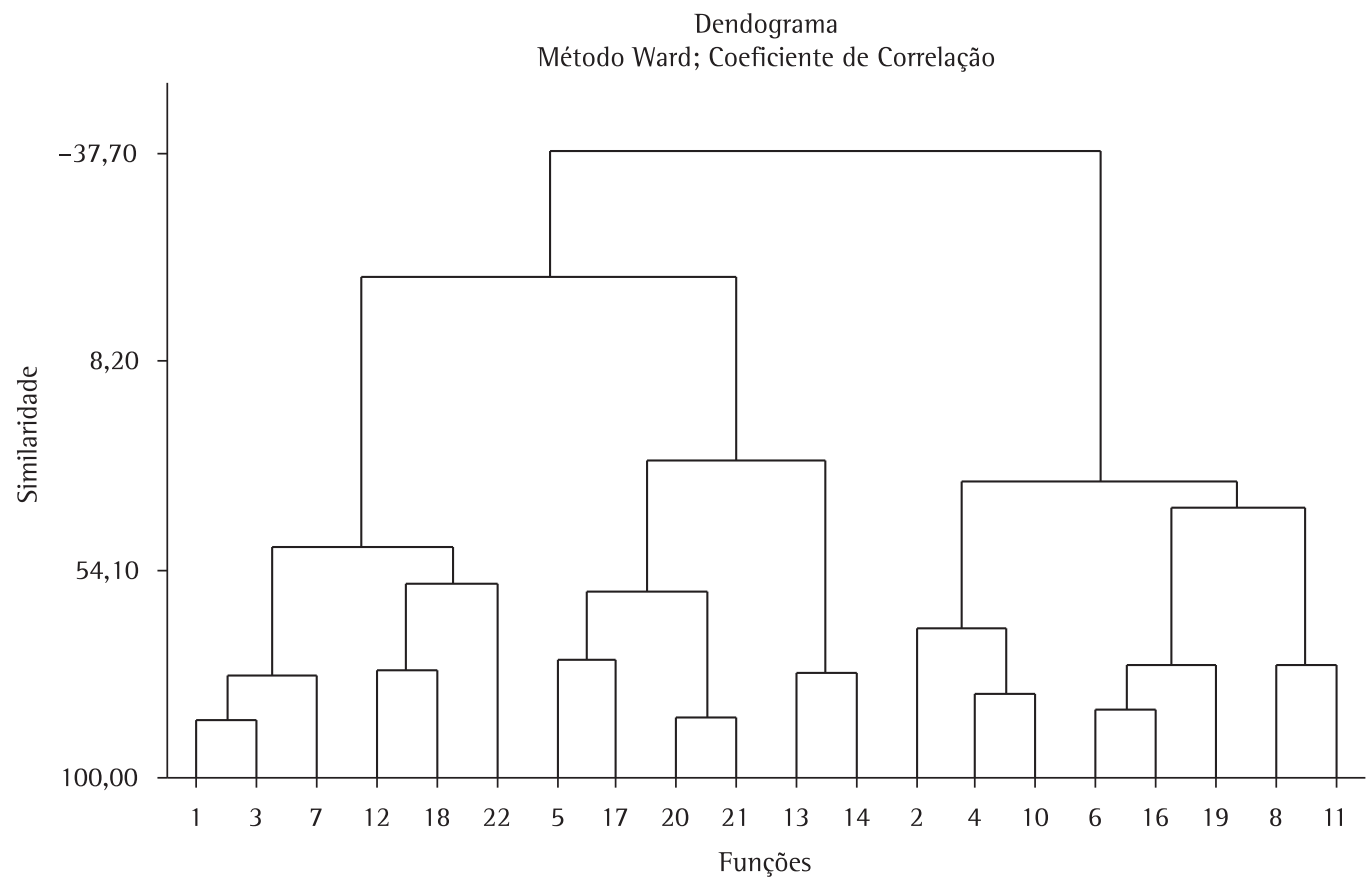

Figura 2. Análise de cluster para as funções do gerente da incubadora. Fonte: Elaborado pelos autores. 
Quadro 4. Agrupamento das funções do gerente das incubadoras.

\begin{tabular}{|c|c|c|c|c|c|c|}
\hline \multirow[b]{2}{*}{ Grupo de afinidade (cluster) } & \multirow[b]{2}{*}{ Funções } & \multicolumn{4}{|c|}{ Tipo de incubadora } & \multirow[b]{2}{*}{ Geral } \\
\hline & & Tradicional & Mista & $\begin{array}{c}\text { Base } \\
\text { tecnológica }\end{array}$ & Design & \\
\hline \multirow{2}{*}{ Focalizar os resultados } & F09 & \multirow{2}{*}{$\begin{array}{c}\text { Muito importante } \\
(4,00)\end{array}$} & \multirow{2}{*}{$\begin{array}{c}\text { Muito importante } \\
(4,00)\end{array}$} & \multirow{2}{*}{$\begin{array}{c}\text { Muito importante } \\
(4,00)\end{array}$} & \multirow{2}{*}{$\begin{array}{c}\text { Muito importante } \\
(4,00)\end{array}$} & \multirow{2}{*}{$\begin{array}{c}\text { Muito importante } \\
(4,00)\end{array}$} \\
\hline & F15 & & & & & \\
\hline \multirow{2}{*}{$\begin{array}{c}\text { Desenvolver competências e } \\
\text { metodologias em gerenciamento de } \\
\text { negócios de base tecnológica }\end{array}$} & F13 & \multirow{2}{*}{$\begin{array}{c}\text { Muito importante } \\
(3,83)\end{array}$} & \multirow{2}{*}{$\begin{array}{c}\text { Muito importante } \\
(3,92)\end{array}$} & \multirow{2}{*}{$\begin{array}{c}\text { Muito importante } \\
(3,83)\end{array}$} & \multirow{2}{*}{$\begin{array}{c}\text { Muito importante } \\
(4,00)\end{array}$} & \multirow{2}{*}{$\begin{array}{c}\text { Muito importante } \\
(3,90)\end{array}$} \\
\hline & F14 & & & & & \\
\hline \multirow{3}{*}{$\begin{array}{c}\text { Fornecer suporte para o } \\
\text { gerenciamento estratégico das } \\
\text { empresas incubadas }\end{array}$} & F02 & \multirow{3}{*}{$\begin{array}{c}\text { Importante } \\
(3,22)\end{array}$} & \multirow{3}{*}{$\begin{array}{c}\text { Importante } \\
(3,22)\end{array}$} & \multirow{3}{*}{$\begin{array}{c}\text { Muito importante } \\
(3,89)\end{array}$} & \multirow{3}{*}{$\begin{array}{c}\text { Muito importante } \\
(3,83)\end{array}$} & \multirow{3}{*}{$\begin{array}{c}\text { Muito importante } \\
(3,54)\end{array}$} \\
\hline & F04 & & & & & \\
\hline & F10 & & & & & \\
\hline \multirow{3}{*}{ Captar e selecionar novas empresas } & F06 & \multirow{3}{*}{$\begin{array}{c}\text { Muito importante } \\
(3,67)\end{array}$} & \multirow{3}{*}{$\begin{array}{c}\text { Importante } \\
(3,00)\end{array}$} & \multirow{3}{*}{$\begin{array}{c}\text { Muito importante } \\
(3,72)\end{array}$} & \multirow{3}{*}{$\begin{array}{c}\text { Muito importante } \\
(3,67)\end{array}$} & \multirow{3}{*}{$\begin{array}{c}\text { Muito importante } \\
(3,51)\end{array}$} \\
\hline & F16 & & & & & \\
\hline & F19 & & & & & \\
\hline \multirow{2}{*}{ Assessorar os planos de negócio } & F08 & \multirow{2}{*}{$\begin{array}{c}\text { Muito importante } \\
(3,83)\end{array}$} & \multirow{2}{*}{$\begin{array}{c}\text { Pouco importante } \\
(2,39)\end{array}$} & \multirow{2}{*}{$\begin{array}{c}\text { Muito importante } \\
(3,67)\end{array}$} & \multirow{2}{*}{$\begin{array}{c}\text { Muito importante } \\
(3,50)\end{array}$} & \multirow{2}{*}{$\begin{array}{c}\text { Importante } \\
(3,35)\end{array}$} \\
\hline & F11 & & & & & \\
\hline & F01 & & & & & \\
\hline Gerenciar multiprojetos de negócios & F03 & $\begin{array}{l}\text { Importante } \\
(2,78)\end{array}$ & $\begin{array}{l}\text { Importante } \\
(2,72)\end{array}$ & $\begin{array}{c}\text { Mutco importante } \\
(3,67)\end{array}$ & $\mid \begin{array}{c}\text { Pouco importante } \\
(2,17)\end{array}$ & $(2,83)$ \\
\hline & F07 & & & & & \\
\hline & F05 & & & & & \\
\hline Promover aprendizagem da & F17 & Importante & Importante & Importante & Pouco importante & Importante \\
\hline incubadora & F20 & $(3,25)$ & $(2,83)$ & $(3,04)$ & $(1,88)$ & $(2,75)$ \\
\hline & F21 & & & & & \\
\hline Monitorar e controlar o desempenho & $\mathrm{F} 12$ & & & & & \\
\hline $\begin{array}{c}\text { da execução dos planos de negócios } \\
\text { das empresas incubadas }\end{array}$ & F18 & $(2,33)$ & $(1,89)$ & $(3,11)$ & $(2,00)$ & $(2,33)$ \\
\hline das empresas incubadas & F22 & & & & & \\
\hline
\end{tabular}

Fonte: Elaborado pelos autores.

utiliza o algoritmo NIPALS (Nonlinear Iterative Partial Least Squares).

Considerou-se como resultados das funções do gerente da incubadora: o tempo que o gerente ocupa cargo de direção da incubadora, pois sua manutenção no cargo depende de seus resultados como gestor; o tempo de existência da incubadora considerando-se que as incubadoras sobrevivem em função de seus resultados; o número de empresas incubadas, porque se a incubadora tem um número expressivo de empresas incubadas isso reflete o trabalho do gerente; o número de empresas graduadas, que é a razão da existência da incubadora; e a obtenção da certificação ISO 9001, considerando-se que a certificação de um sistema de gestão da qualidade é um meio de assegurar a previsibilidade e melhoria dos resultados.

0 Minitab $15^{\oplus}$ calcula o PLS prevendo os resultados por meio das funções do gerente da incubadora. Primeiramente foi realizado o modelo do PLS e uma análise de resíduos para verificar sua normalidade. Em caso de anormalidade dos resíduos, elimina-se o seu elemento gerador e recalcula-se o modelo. Repete-se o processo até que se obtenha a normalidade dos resíduos e, só então, se faz a análise dos resultados do PLS.

Uma das principais questões que se coloca na Análise dos Componentes Principais é o critério de escolha do número de componentes a manter. Kim e Mueller (1978) citam que o método mais conhecido e utilizado é o de Kaiser, que propõe considerar apenas os autovalores superiores a 1. No entanto, esta condição não é suficiente. Para Johnson e Wichern (1998), os primeiros componentes devem absorver de 80\% a $90 \%$ da variação total, para serem usados como substitutos dos dados originais e, de acordo com o critério de Kaiser, deve-se excluir os componentes cujos autovalores são inferiores a 1. Nesta pesquisa, será adotado o diagrama de autovalores, em que os componentes principais absorvam cerca de $80 \%$ da variação total.

O PLS apresenta os coeficientes das funções do gerente da incubadora para cada resultado analisado. Coeficientes negativos indicam que a função tem pouca importância para a obtenção do resultado e coeficientes positivos indicam que a função tem muita importância para se alcançar o resultado, apresentado no Quadro 5.

Estatisticamente significa que se o gerente da incubadora pretende obter um determinado resultado, ele deve alocar maior parte de seu tempo para as funções consideradas de muita importância para que esse resultado seja alcançado, evitando funções que reduzam a possibilidade de sucesso. 
Quadro 5. Funções do gerente da incubadora consideradas de maior e menor importância para o resultado.

\begin{tabular}{|c|c|c|}
\hline Resultado & $\begin{array}{l}\text { Funções de muita importância } \\
\text { para o resultado }\end{array}$ & $\begin{array}{l}\text { Funções de pouca importância } \\
\text { para o resultado }\end{array}$ \\
\hline Tempo do gerente no cargo de direção & \multirow[b]{2}{*}{$\begin{array}{l}\text { F20 - Criar e gerenciar um banco } \\
\text { de dados de lições aprendidas pelas } \\
\text { empresas incubadas ao longo de seu } \\
\text { desenvolvimento } \\
\text { F16 - Fornecer orientação para potenciais } \\
\text { empreendedores } \\
\text { F04 - Gerenciar relacionamento dos } \\
\text { empreendedores incubados com os } \\
\text { interessados em seu empreendimento } \\
\text { (fornecedores, clientes, fundos de } \\
\text { investimento, organismos governamentais } \\
\text { de fomento) }\end{array}$} & \multirow[b]{2}{*}{$\begin{array}{l}\text { F10 - Monitorar e controlar o desempenho } \\
\text { de cada plano de negócio das empresas } \\
\text { incubadas } \\
\text { F22 - Fornecer um conjunto de ferramentas } \\
\text { às empresas incubadas sem a preocupação } \\
\text { de padronizar } \\
\text { F19 - Arquivar, atualizar e disponibilizar } \\
\text { para fácil acesso a documentação dos } \\
\text { planos de negócio das empresas incubadas }\end{array}$} \\
\hline $\begin{array}{c}\text { PLS std coefficient plot } \\
\text { (response is tempo no cargo de direçăo) } \\
7 \text { components }\end{array}$ & & \\
\hline Tempo de existência da incubadora & \multirow[b]{2}{*}{$\begin{array}{l}\text { F05 - Relatar o status do plano de } \\
\text { negócio das empresas incubadas para a } \\
\text { diretoria e conselho da incubadora, bem } \\
\text { como os demais parceiros } \\
\text { F02 - Participar do planejamento } \\
\text { estratégico das empresas incubadas } \\
\text { F06 - Identificar, selecionar e priorizar } \\
\text { novas empresas que queiram incubar } \\
\text { F08 - Orientar a elaboração dos planos de } \\
\text { negócio das empresas incubadas }\end{array}$} & \multirow[b]{2}{*}{$\begin{array}{l}\text { F10 - Monitorar e controlar o desempenho } \\
\text { de cada plano de negócio das empresas } \\
\text { incubadas } \\
\text { F12 - Desenvolver e manter um } \\
\text { "placar visível" que permita monitorar } \\
\text { simultaneamente todos os planos de } \\
\text { negócio das empresas incubadas } \\
\text { F01 - Gerenciar um ou mais portfólios de } \\
\text { planos de negócio. Por exemplo, a empresa } \\
\text { pode incubar com um plano de negócio e } \\
\text { posteriormente desenvolver outros planos } \\
\text { de negócio que passam a ser também } \\
\text { gerenciados pela incubadora } \\
\text { F13 - Oferecer assessoria especializada para } \\
\text { os empreendedores incubados }\end{array}$} \\
\hline $\begin{array}{c}\text { PLS std coefficient plot } \\
\text { (response is tempo existência da incubadora) } \\
7 \text { components }\end{array}$ & & \\
\hline Número de empresas incubadas & \multirow[b]{2}{*}{$\begin{array}{l}\text { F06 - Identificar, selecionar e priorizar } \\
\text { novas empresas que queiram incubar } \\
\text { F21 - Criar e gerenciar um banco de } \\
\text { dados de risco acerca dos planos de } \\
\text { negócio das empresas incubadas } \\
\text { F16 - Fornecer orientação para potenciais } \\
\text { empreendedores }\end{array}$} & \multirow[b]{2}{*}{$\begin{array}{l}\text { F22 - Fornecer um conjunto de ferramentas } \\
\text { às empresas incubadas sem a preocupação } \\
\text { de padronizar } \\
\text { F08 - Orientar a elaboração dos planos de } \\
\text { negócio das empresas incubadas } \\
\text { F10 - Monitorar e controlar o desempenho } \\
\text { de cada plano de negócio das empresas } \\
\text { incubadas }\end{array}$} \\
\hline $\begin{array}{c}\text { Taxa de explicação: } 96,96 \% \\
\text { P-Value: } 0,000\end{array}$ & & \\
\hline Número de empresas graduadas & \multirow[b]{2}{*}{$\begin{array}{l}\text { F05 - Relatar o status do plano de } \\
\text { negócio das empresas incubadas para a } \\
\text { diretoria e conselho da incubadora, bem } \\
\text { como os demais parceiros } \\
\text { F08 - Orientar a elaboração dos planos de } \\
\text { negócio das empresas incubadas } \\
\text { F17 - Reduzir o tempo de incubação } \\
\text { F14 - Desenvolver competências nos } \\
\text { empreendedores incubados e em seus } \\
\text { colaboradores, incluindo treinamento } \\
\text { F06 - Identificar, selecionar e priorizar } \\
\text { novas empresas que queiram incubar }\end{array}$} & \multirow[b]{2}{*}{$\begin{array}{l}\text { F10 - Monitorar e controlar o desempenho } \\
\text { de cada plano de negócio das empresas } \\
\text { incubadas } \\
\text { F12 - Desenvolver e manter um } \\
\text { "placar visível" que permita monitorar } \\
\text { simultaneamente todos os planos de } \\
\text { negócio das empresas incubadas } \\
\text { F01 - Gerenciar um ou mais portfólios de } \\
\text { planos de negócio. Por exemplo, a empresa } \\
\text { pode incubar com um plano de negócio e } \\
\text { posteriormente desenvolver outros planos } \\
\text { de negócio que passam a ser também } \\
\text { gerenciados pela incubadora }\end{array}$} \\
\hline 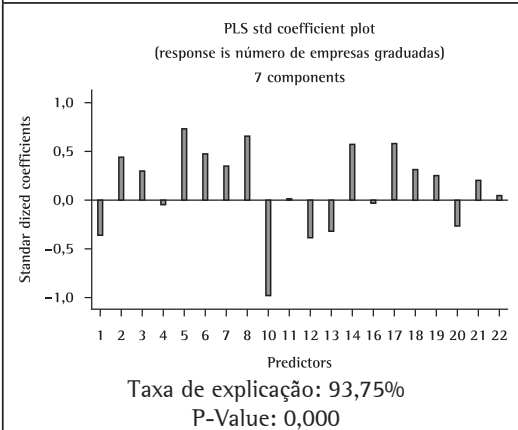 & & \\
\hline
\end{tabular}

Fonte: Elaborado pelos autores. 
Quadro 5. Continuação...

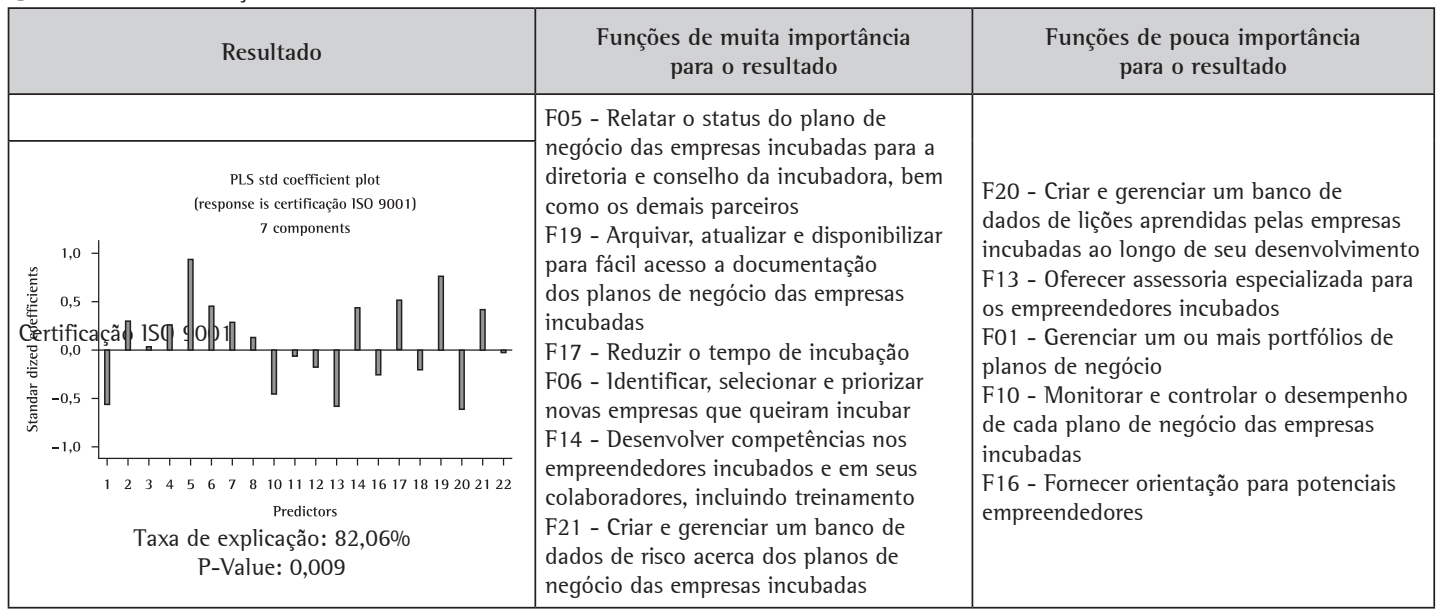

Fonte: Elaborado pelos autores.

\subsection{Análise qualitativa dos dados}

Após a análise estatística, os resultados obtidos foram enviados por e-mail aos respondentes para sua apreciação com o pedido de comentários e sugestões a respeito das análises e também dos nomes dados aos grupos. Dos quinze e-mails enviados apenas dois retornaram.

Um dos respondentes concordou com a grande maioria das nomenclaturas dos grupos e fez apenas duas sugestões de novos nomes. 0 outro respondente fez uma análise um pouco mais profunda. Segundo o respondente, é muito importante que as incubadoras tenham processos padronizados mas ele acredita que atualmente ainda não é um fator determinante. A certificação 1SO 9001 como padrão de sucesso das incubadoras ainda não condiz com a realidade. $\mathrm{Na}$ visão deste respondente, uma tarefa muito importante do gerente da incubadora é a captação de novas empresas para a incubação. Destaca-se que o número de empresas incubadas não evidencia que a incubadora é bem sucedida, são necessários outros parâmetros não disponíveis para pesquisa, principalmente resultados financeiros contínuos das empresas (antes e após a incubação), bem como número de empregos diretos e indiretos gerados, tempo de sobrevivência após sua graduação. Um número maior de empresas pode conferir maior prestígio à incubadora e ao seu gerente, mas isso não implica que ela possa ser caracterizada como bem sucedida em suas atividades.

Sobre o resultado "Tempo do gerente em cargo de direção", o respondente afirma que os recursos da instituição possuem mais força para a manutenção do gerente no cargo do que seus resultados como gestor. Ele complementa dizendo que a grande maioria dos gerentes das incubadoras é da instituição a qual pertence. Como as incubadoras são órgãos híbridos, sustentadas por recursos públicos e pelo apoio de muitos parceiros, quem financia os gerentes são bolsas fornecidas por órgãos como o CNPq e a FAPEMIG. 0 respondente prossegue dizendo que são raros os gerentes contratados com dedicação exclusiva para a incubadora pois esta não é autossustentável e depende de seus parceiros.

Como a taxa de retorno dos e-mails foi baixíssima, apenas dois, optou-se por entrevistar os gerentes das incubadoras para que estes realizassem uma análise dos resultados obtidos. Foram entrevistados três gerentes das incubadoras da RMl, utilizando-se um roteiro de entrevista baseado nos resultados estatísticos obtidos. As entrevistas duraram em média uma hora e meia. Os gerentes entrevistados (E1; E2 e E3) possuíam, em cargo de gerência, 121, 45 e 78 meses, respectivamente.

A análise feita pelos entrevistados acerca das funções de maior importância para a obtenção dos resultados está descrita a seguir:

\section{Entrevistado E1:}

Nas incubadoras com bons resultados existe uma visão de longo prazo e ênfase do gerente em praticar a governança perante seus investidores.

O gerente deve utilizar todas as oportunidades e meios para reportar o desempenho da incubadora. A confiança se adquire com o tempo e com as conquistas obtidas. $O$ resultado depende da confiança que todos os envolvidos possuem no gerente da incubadora. Mas deve-se destacar que o gerente possui grande dependência de recursos externos.

Verifica-se nas respostas do entrevistado E1, ênfase na função "Relatar o status do plano de negócio das empresas incubadas para a diretoria e conselho da incubadora, bem como os demais parceiros (F05)" e 
na confiança obtida, com o tempo, pelo gerente da incubadora por meio de seus resultados.

\section{Entrevistado E2:}

Quanto maior o tempo de experiência na gerência da incubadora, maior a sensibilidade do gerente para a formação do empreendedor. Nossos empreendedores, em sua maioria, possuem habilidades técnicas, mas são carentes em comportamento empreendedor, que cabe a nós desenvolvermos. $O$ tempo de experiência do gerente da incubadora e seu histórico transmitem confiança.

0 entrevistado E2 enfatiza a função "Desenvolver competências nos empreendedores incubados e em seus colaboradores, incluindo treinamento (F14)", que se mostrou relevante para a obtenção dos resultados. Destaca também a experiência do gerente da incubadora.

Entrevistado E3:

O gerente tem consciência de que a empresa logo sairá da incubadora e é necessário que ela seja independente... O empreendedor, juntamente com seus colaboradores, precisa ter um comportamento empresarial maduro para lidar com as adversidades do mercado, ou seja, saber negociar, se comunicar, liderar, gerir pessoas...

O gerente experiente é capaz de ajudar as empresas incubadas na busca de soluções para encontrarem o caminho do sucesso. Ele consegue enxergar muitas vezes o que o empreendedor não quer admitir: que apesar do seu produto ser brilhante ainda não tem um mercado desenvolvido, ou que a empresa precisa se sustentar com alguma outra atividade para financiar o desenvolvimento da sua inovação... Enfim são inúmeros casos.

ldentifica-se, nas palavras do entrevistado E3, ênfase na função "Desenvolver competências nos empreendedores incubados e em seus colaboradores, incluindo treinamento (F14)".

Quanto mais experiente for o gerente mais apto ele está para orientar novos empreendedores. Isto porque ele já tem conhecimento sobre como abrir uma empresa, quais os passos para legalizar, como buscar financiamento, enfim, o processo de aprendizagem do gerente é cumulativo. Cada empresa é única e ele aprende cada vez mais. O processo de seleção é fundamental para o sucesso da incubadora.

A função "Identificar, selecionar e priorizar novas empresas que queiram incubar (F06)" é identificada na fala do entrevistado E3. Este entrevistado destaca a necessidade do gerente da incubadora ser experiente.

Percebe-se que todos os entrevistados fazem referência à experiência do gerente de incubadora. Este destaque denota que os entrevistados acreditam que o bom desempenho das funções é consequência do perfil do gerente.
Quanto às funções do gerente que restringem os resultados, os comentários dos entrevistados são:

Entrevistado E1:

A maioria dos novos gerentes é bolsista. Este fato compromete todo o trabalho, pois a remuneração acaba não sendo condizente com suas funções, além de ser concedida por tempo limitado. Acabam focando suas funções em resultados de curto prazo.

$O$ contexto e potencial da empresa são mais relevantes que seu plano de negócio.

"Arquivar, atualizar e disponibilizar para fácil acesso a documentação dos planos de negócio das empresas incubadas" é função que deve ser delegada para a secretária da incubadora. Colocar o gerente da incubadora para desempenhar esta função é desperdício de recursos.

0 entrevistado concorda que a função "Arquivar, atualizar e disponibilizar para fácil acesso a documentação dos planos de negócio das empresas incubadas (F19)" tem pouca importância para a obtenção do resultado "Tempo no cargo de direção".

\section{Entrevistado 2:}

Gerentes com pouca experiência tendem a enfatizar os controles e a busca de resultados imediatistas, utilizando o plano de negócio como o principal parâmetro de avaliação do empreendedor, pois ele é um instrumento auditável. Oferecem várias capacitações e assessorias especializadas sem compreenderem a necessidade do empreendedor e os resultados esperados. Normalmente isso resulta em sufocar o empreendedor.

Existe uma ênfase em resultados no curto prazo por meio de controle excessivo. Normalmente isso ocorre devido a exigências de resultados imediatistas por parte dos investidores da incubadora.

Nas incubadoras, a grande maioria das assessorias é terceirizada e sob demanda. Cabe ao gerente da incubadora acessar as consultorias e disponibilizá-las aos empreendedores incubados. A estrutura das incubadoras é reduzida dificultando o acompanhamento do plano de negócio. Este fato se agrava em empreendimentos com ênfase em tecnologia, que dependem de conhecimentos específicos disponíveis, muitas vezes, em centros de pesquisa e Universidades. Estes casos necessitam incorporar ao plano de negócio elementos que contemplem os aspectos tecnológicos.

0 entrevistado afirma que a função "Monitorar e controlar o desempenho de cada plano de negócio das empresas incubadas (F10)" é pouco importante para se obter resultados e destaca como causas a pouca experiência do gerente da incubadora, a pressão dos investidores por resultados e especificidades tecnológicas dos planos de negócio. 


\section{Entrevistado 3:}

As funções do gerente são complementares. Acho errado afirmar que, quanto mais o gerente monitora e acompanha a empresa incubada, mais ele restringe os resultados da incubadora. Pelo contrário, mais chance o gerente tem de resolver em tempo hábil as deficiências da empresa. $O$ excesso de monitoramento e controle sem flexibilidade, impedindo a empresa incubada de mudanças e alterações é prejudicial, pois não se abre espaço para a correção de possíveis falhas.

0 entrevistado salienta que se o gerente da incubadora desempenhar em excesso a função "Monitorar e controlar o desempenho de cada plano de negócio das empresas incubadas (F10)" ele vai limitar os resultados da incubadora.

Afirmar que a função oferecer assessoria especializada para os empreendedores incubados restringe os resultados da incubadora, tem que tomar muito cuidado para explicar. As empresas são de naturezas diferentes e demandam soluções diferenciadas. O gerente da incubadora, por mais tempo que tenha de experiência, não possui TODO o conhecimento. As empresas muitas vezes demandam soluções especializadas como, por exemplo, registrar um produto biológico, exportar material vivo, patentear software. De um modo geral os gerentes com mais tempo de experiência buscam cada vez mais assessorias especializadas para as empresas por conhecerem suas limitações.

Soluções empacotadas iguais para todo o mundo sempre causavam problemas e não atendiam às diferentes necessidades. E tem mais uma observação: as empresas estão em estágios de desenvolvimento diferentes. Tem empresas, com um ano apenas, fazendo $P \& D$ como tem empresas na reta final $d a$ incubação já exportando. Fica difícil padronizar soluções nesses casos.

0 entrevistado enfatiza que a função "Oferecer assessoria especializada para os empreendedores incubados (F13)" é de grande importância e discorda do reduzido grau de importância que lhe foi ofertado. Destaca a importância da experiência do gerente da incubadora e que as empresas incubadas possuem estágios de desenvolvimento diferentes e especificidades tecnológicas. Sugere a incorporação na função das palavras "diferenciada e individualizada".

A premissa não é quanto mais organizado melhor? Sendo assim, como pode haver restrições nos resultados quando o gerente executa as funções de arquivar, atualizar e disponibilizar para fácil acesso a documentação dos planos de negócio das empresas incubadas?
0 entrevistado questiona se a função "Arquivar, atualizar e disponibilizar para fácil acesso a documentação dos planos de negócio das empresas incubadas (F19)" tenha pouca importância para a obtenção do resultado "Tempo no cargo de direção".

Percebe-se, nas entrevistas, que a experiência do gerente da incubadora é preponderante na distribuição do seu tempo para desempenhar suas funções e obter a confiança e os recursos disponibilizados pelos stakeholders.

Considerando os resultados obtidos por David et al. (2002) onde identificou-se que nas incubadoras consideradas benchmarking os gerentes investem $50 \%$ do seu tempo aconselhando os empreendedores incubados e o tempo restante em questões administrativas, o gerente da incubadora deveria alocar grande parte de seu tempo na função "Desenvolver competências nos empreendedores incubados e em seus colaboradores, incluindo treinamento (F14)". Esta função é considerada pouco importante apenas para o resultado "Tempo no cargo de direção". Verifica-se que as funções consideradas de maior importância para a obtenção de todos os resultados são: "Participar do planejamento estratégico das empresas incubadas (FO2)", "Distribuir recursos disponíveis entre as empresas incubadas (FO3)" e "Relatar o status do plano de negócio das empresas incubadas para a diretoria e conselho da incubadora, bem como os demais parceiros (FO5)".

As funções do gerente da incubadora consideradas mais importantes para se alcançar os resultados são as ações que visam minimizar os problemas das incubadoras do tipo "desenvolvimento econômico local”, identificados na pesquisa de Albert e Gaynor (2003): escassez de recursos estáveis e duráveis; qualidade da gestão e dos serviços prestados que possui grande dependência do gerente; escassez de governança; risco de conflitos sobre objetivos; entraves burocráticos; e tempo gasto na negociação com os diferentes parceiros.

Todos os gerentes da RMl consideram como funções muito importantes "Monitorar e controlar o desempenho da incubadora (F09)" e "Fornecer orientação aos empreendedores incubados (F15)". Relembrando que estas funções, por não apresentarem variabilidade, foram excluídas das análises estatísticas.

Os resultados complementam as pesquisas de Albert e Gaynor (2003), Gillotti e Ziegelbauer (2006) e Adkins (2007) ao detalhar e analisar as funções do gerente da incubadora.

Nota-se que a atuação dos gerentes é fundamental para a obtenção de resultados positivos pela incubadora. Entre os requisitos desejáveis para o bom desempenho do cargo estão a detenção de 
conhecimentos tão variados quanto variadas são as funções. Além disso, espera-se que o gerente possua uma razoável experiência em funções gerenciais que The permita trafegar pelas diferentes áreas e oferecer soluções para os problemas específicos de cada empresa incubada.

\section{Conclusões}

As funções dos gerentes das incubadoras podem ser representadas pelas funções do PMO, sendo identificadas 22 funções a serem desempenhadas pelo gerente da incubadora. É consenso entre os respondentes das incubadoras da RMl que as funções mais importantes do gerente da incubadora são: monitorar e controlar o desempenho geral da incubadora (F09) e fornecer orientação para os empreendedores incubados (F15). Entretanto, a pesquisa mostra que a função monitorar e controlar o desempenho de cada plano de negócio das empresas incubadas (F10) é pouco importante para a obtenção dos "resultados da incubadora".

As funções relatar o status do plano de negócio das empresas incubadas para a diretoria e conselho da incubadora, bem como os demais parceiros (F05), e identificar, selecionar e priorizar novas empresas que queiram incubar (F06) são importantes para a obtenção dos resultados da incubadora.

Conclui-se que gerentes com menor tempo de experiência tendem a controlar de modo inflexivel os empreendedores e oferecer-lhes muitas assessorias generalizadas. Essa visão de curto prazo pode inibir os resultados da incubadora. Por outro lado, os gerentes mais experientes buscam potencializar os resultados de longo prazo, desenvolvendo competências nos empreendedores e promovendo a abertura de canais de comunicação com a diretoria, conselho da incubadora e demais parceiros além de identificar, selecionar e priorizar novas empresas que queiram incubar.

É importante ressaltar que esta pesquisa limitou-se, quanto ao objeto de estudo, aos gerentes das incubadoras associadas à Rede Mineira de Inovação, um universo de 25 incubadoras. Sugere-se, para futuras pesquisas, ampliar a amostra, abrangendo incubadoras de outros Estados do País, confrontando o perfil e a atuação de gerentes das incubadoras das diversas regiões.

Recomenda-se utilizar outros parâmetros como sendo "resultados da incubadora", tais como, a receita direta e indireta gerada pelas empresas incubadas e graduadas, o número de empresas geradas e o lucro das empresas incubadas e graduadas. Esses parâmetros podem ser incluídos como objeto em futuras pesquisas, possibilitando que o conceito de resultado esteja em sintonia com o pensamento do gerente e dos stakeholders ligados às incubadoras.

A ênfase dos entrevistados na experiência do gerente como fator preponderante para a obtenção dos resultados da incubadora sugere a execução de pesquisas que identifiquem qual perfil de gerente da incubadora propicia melhores resultados.

\section{Referências}

ADKINS, D. Five "musts" for business incubator success. President \& CEO, National Business Incubation Association. Economic Development America, p. 19-21, 2007.

AERTS, K.; MATTHYSSENS, P.; VANDENDEMPT, K. Critical role and screening practices of European business incubators. Technovation, v. 27, p. 254-267, 2007. http://dx.doi.org/10.1016/j.technovation.2006.12.002

ALBERT, P.; GAYNOR, L. Incubators: growing up, moving out: a review of literature. France: CERAM Sophia Antipolis, 2001.

ALBERT, P.; GAYNOR, L. National contexts, incubator families and trends in incubation - views from four countries. In: INTERNATIONAL COUNCIL FOR SMALL BUSINESS, WORLD CONFERENCE, 48., 2003, Northern Ireland. Proceedings...2003. p. 9-19.

ALLEN CONSULTING GROUP. Program \& the intelligent island incubator. The Allen Consulting Group, 2003.

ASGHARI, H. A conceptual model for job analysis of incubators managers based on ONET model. In: WORRLD CONFERENCE ON SCIENCE AND TECHNOLOGY PARKS - IASP, 25., 2008, Johannesburg, South Africa. Proceedings...2008.

BABBIE, E. Métodos de pesquisas de survey. 3. ed. Belo Horizonte: UFMG, 2005.

BARROW, C. Incubators: a realist's guide to the world's new business accelerators. Chichester, New York: John Wiley \& Sons, 2001

BIZZOTO, C. E. N. Modelo de maturidade de incubadoras de empresas. In: SEMINÁRIO NACIONAL DE PARQUES TECNOLÓGICOS E INCUBADORAS DE EMPRESAS, 13., 2003. Anais... Brasília: ANPROTEC, 2003. p. 41-52.

BOLLINGTOFT, A.; ULHOI, J. The networked business incubator: leveraging entrepreneurial agency. Journal of Business Venturing, v. 20, n. 2, p. 265-290, 2005. http:// dx.doi.org/10.1016/j.jbusvent.2003.12.005

BRIDGES, D.; CRAWFORD, J. K. A project office - Where and what type. In: PROJECT MANAGEMENT INSTITUTE ANNUAL SEMINARS \& SIMPOSIUM, 2001, Nashville. Proceedings...2001.

CAMPBELL, C. Change agents in the new economy: business incubators and economic development. Economic Development, v. 3, n. 2, p. 56-59, 1989.

CAMPBELL, D. T.; STANLEY, J. Delineamentos experimentais e quase-experimentais de pesquisa. São Paulo: EPUEDUSP, 1979. $138 \mathrm{p}$.

CASEY, W.; PECK, W. Choosing the right PMO setup. PM Network, v. 15, n. 2, p. 40-47, 2001. 
CRAWFORD, J. K. The strategic project office: business case and implementation strategy. PM Solutions White Paper, 2001. Disponivel em: <http://www.pmsolutions. com>. Acesso em: 11 abr. 2009.

CUNHA, N. C. V. O Gerente de incubadora atuando como agente de interação universidade-empresa e de captação de novos empreendimentos. In: CASTRO, E.; SOUZA, L. (Ed.). Empreendedorismo - Competência essencial para PME's. Brasília: ANPROTEC, 2001. p. 145-158.

DAl, C. X.; WELLS, W. G. An exploration of project management office features and their relationship to project performance. International Journal of Project Management, n. 22, p. 523-532, 2004. http://dx.doi. org/10.1016/j.jproman.2004.04.001

DAVID, J. C.; MALAN, J.; LALKAKA, R. Improving business incubator performance through benchmarking and evaluation: lessons learned from europe. In: INTERNATIONAL CONFERENCE ON BUSINESS INCUBATION, 16., Toronto, Canada, 2002. Proceedings...2002.

FERREIRA, M. P. et al. Gestão por indicadores de desempenho: resultados na incubadora empresarial tecnológica. Produção, v. 18, n. 2, p. 302-318, 2008.

FINK, A. The Survey handbook. London:SAGE publications, 1993.

FORZA, C. Survey research in operations management: a processbased perspective. International Journal of Operations \& Production Management, v. 22, n. 2, p. 152-194, 2002. http://dx.doi.org/10.1108/01443570210414310

GIANNINI, A. Estamos prontos para a implementação de um PMO? Mundo PM, n. 9, p. 26-28, 2006.

GlL, A. C. Como elaborar projetos de pesquisa. 4. ed. São Paulo: Atlas. 2002.

GILLOTTI, T.; ZIEGELBAUER, R. Seven components of a successful business incubator. University of WisconsinExtension. Let's Talk Business, n. 119, 2006.

GUIMARÃES, C. L.; SENHORAS, E. M.; TAKEUCHI, K. P. Empresa júnior e incubadora tecnológica: duas facetas de um novo paradigma de interação empresa-universidade. In: SIMPÓSIO DE ENGENHARIA DE PRODUÇÃO SIMPEP, 2003, Bauru. Anais... 2003.

HACKETT, S. M.; DILTS, D. M. A systematic review of business incubation research. Journal of SurveyTechnology Transfer, v. 29, n. 1, p. 55-82, 2004

HAIR JUNIOR, J. F. et al. Fundamentos de métodos de pesquisa em administração. Porto Alegre: Bookman, 2005.

HAIR JUNIOR, J. F. et al. Multivariate data analysis. 5. ed. Upper Saddle River: Prentice Hall, 1998.

HARMAN, P.; READ, L. Supporting incubation in the UK through the development of benchmarks. In: UKBl: INTERNATIONAL COUNCIL FOR SMALL BUSINESS, WORLD CONFERENCE, 48., 2003, Northern Ireland. Proceedings... 2003. p. 2.

HELLAND, 1. S. On the structure of partial least squares regression. Communications in Statistics, Part B: Simulation and Computations, v. 17, p. 581-607, 1988. http://dx.doi.org/10.1080/03610918808812681

HOBBS, B.; AUBRY, M. A multi-phase research program investigating Project Management Offices (PMOs): the result of phase 1 . Project Management Institute, v. 38, n. 1, p. 74-86, 2007.

JOHNSON, R. A.; WICHERN, D. W. Applied multivariate statistical analysis. 4. ed. New Jersey: Prentice Hall, 1998.
KATE, J. Program office: an enterprise view. EUA, 2000.

KENDALL, G. J.; ROLLINS, S. C. Advanced portfolio management and the PMO Multiplaying ROI at warp speed. Flórida: J. Ross Publishing, 2003.

KIM, J.; MUELLER, C. W. Factor analysis, statistical methods and practical issues. Beverly Hills: Sage Publication, 1978.

LENDNER, C. Management, professionals and funding of university business incubators worldwide. In: INTERNATIONAL COUNCIL FOR SMALL BUSINESS, WORLD CONFERENCE, 48., 2003, Northern Ireland. Proceedings... 2003. p. 3-5.

MALHOTRA, N. K. Pesquisa de marketing: uma orientação aplicada. 4. ed. Porto Alegre: Bookman, 2006.

MARKMAN, G. D. et al. Entrepreneurship and university-based technology transfer. Journal of Business Venturing, v. 20, n. 2, p. 241-263, 2005. http://dx.doi.org/10.1016/j. jbusvent.2003.12.003

MEDEIROS, J. A. et al. Pólos, parques e incubadoras: a busca da modernização e competitividade. CNPq IBICT, SENAl, 1992.

MORAIS, E. F. C. Entre a genialidade e o malabarismo. In: SALOMÃO, J. R. (Org.). As incubadoras de empresas pelos seus gerentes: uma coletânea de artigos. Brasília: ANPROTEC, 1998.

MORAIS, E. F. C. Manual de acompanhamento e autoavaliação de incubadoras e empresas incubadas. Brasília: ANPROTEC, 1998.

MOREIRA, J. H. Modelo de gestão para incubação de empresas orientado a capital de risco. Dissertação (Mestrado)-Universidade Federal de Santa Catarina, Florianópolis, 2002.

MURPHY, R. E. The role of the project support office. In: PROJECT MANAGEMENT INSTITUTE SEMINARS \& SYMPOSIUM, 1996, Massachusetts. Proceedings...1996.

NUNNALLY, J. C.; BERNSTEIN, I. H. Psychometric theory. New York: McG. Hill, 1994.

PETERS, L.; RICE, M.; SUNDARARAJAN, M. The role of incubator in the entrepreneurial process. Journal of Technology Transfer, v. 29, n. 1, p. 83-91, 2004. http:// dx.doi.org/10.1023/B:JOTT.0000011182.82350.df

PHAN, P. H.; SIEGEL, D. S.; WRIGHT, M. Science parks and incubators: observations, synthesis and future research. Journal of Business Venturing, v. 20, n. 2, p. 165-182, 2005. http://dx.doi.org/10.1016/j.jbusvent.2003.12.001

PINSONNEAULT, A.; KRAEMER, K. L. Survey research methodology in management information systems: in assessment. Journal of Management Information Systems, v. 10, n. 2, p. 75-105, 1993.

PRADO, D. Gerenciamento de projetos nas organizações. Belo Horizonte: EDG, 2003.

PRADO, D. Planejamento e controle de projetos. Belo Horizonte: EDG, 2000.

PROJECT MANAGEMENT INSTITUTE - PMI. Relatório de estudo de benchmarking em gerenciamento de projetos. 2008. Disponível em: <http://www.pmi.org. br>. Acesso em: 10 fev. 2009.

RAD, P. F.; RAGHAVAN, A. Establishing an organizational project office. AACE International Transactions, 2000. 
RAPINI, M. S. Interação universidade-empresa no Brasil: evidências do diretório dos grupos de pesquisa do CNPq. Estudos Econômicos, Instituto de Pesquisas Econômicas, v. 37, p. 211-233. 2007.

REDE MINEIRA DE INOVAÇÃO - RMI. Catálogo 2008/2009 da Rede Mineira de Inovação. 2008.

RICE, M.; ABETTI, P. Intervention mechanisms utilized by business incubators to influence the critical success factors of new ventures: an exploratory study. In: BABSON COLLEGE ENTREPRENEURSHIP CONFERENCE - INSEAD, 1992, Fontainebleau, France. Proceedings...

SANTOSUS, M. Why you need project management office. ClO Magazine, 2003.

SIEGEL, D. S.; Westhead, P.; Wright, M. Assessing the impact of university science parks on research productivity: exploratory firm-level evidence from the UK. International Journal of Industrial Organisation, v. 21, n. 9, p. 1537-1550, 2003. http://dx.doi.org/10.1016/ S0167-7187(03)00086-9

SILVA, E. A. Modelagem e otimização do processo de texturização por falsa torção. 2009. Dissertação (Mestrado em Engenharia de Produção)-UNIFEl, Itajubá, 2009.

SIMSEK, Z. Sample surveys via electronic mail: a comprehensive perspective. RAE - Revista de Administração de Empresas, v. 39, n. 1, p.77-83, 1999.
SMILOR, R. W.; GILL, M. D. J. The new business incubator: linking talent technology, capital, and know-how. Lexington, MA, 1986.

TINNIRELlO, P. C. New directions in Project management. Florida: Auerbach Publications, 2001. http://dx.doi. org/10.1201/9781420000160

UNITED KINGDOM BUSINESS INCUBATION - UKBI. The national business incubation framework: summary report. 2004.

VARGAS, R. V. Gerenciamento de projetos: estabelecendo diferenciais competitivos. 5. ed. Rio de Janeiro: Brasport, 2003.

VERZUH, E. The fast forward MBA in PROJECT Management. New York: John Wiley \& Sons, 1999.

WIGGINS, J.; GIBSON, D. V. Overview of US incubators and the case of Austin technology incubator. International Journal of Entrepreneurship and Innovation Management, v. 3, n. 1/2, p. 56-66, 2003. http://dx.doi. org/10.1504/IJEIM.2003.002218

YACOUB, F.; MACGREGOR, J. F. Product optimization and control in the latent variable space of nonlinear PLS models. Chemometrics and Intelligent Laboratory Systems, v. 70, p. 63-74, 2004. http://dx.doi. org/10.1016/j.chemolab.2003.10.004

\title{
The impact of the functions performed by managers in the incubator's results: a Survey accomplished by "Rede Mineira de Inovação"
}

\begin{abstract}
The purpose of this study was to evaluate the relationship between the functions performed by managers and the results obtained by the incubator. The results considered were the following: the time period for manager's take over, the incubator's existence time period, the number of incubated companies, the number of firms graduated, and the achievement of ISO 9001 certification. The functions performed by managers of incubators are based on the Project Management Office (PMO). These functions are then grouped and their descriptions are adapted to the context of the incubators. A questionnaire was prepared and sent by e-mail to business incubators in the "Rede Mineira de Inovação". The data were collected, processed and analyzed statistically. The main results obtained showed that, the functions that contribute the most to the results of the incubator are: participating in the incubated enterprisers strategic planning and distributing available resources to them; and the functions that contribute the least to the results are: following up and checking out the performance of each business plan of the incubated companies.
\end{abstract}

Keywords

Business incubators. Incubator manager. Manager's functions. Project management office. 